\title{
The Role of the Host Local Population in the Process of Migrants' Adaptation
}

\author{
Vsevolod Konstantinov \\ Department of General Psychology, Penza State University, 40, Krasnaya Street, Penza 440026, Russia; \\ dep_op@pnzgu.ru
}

Received: 11 June 2017; Accepted: 7 August 2017; Published: 11 August 2017

\begin{abstract}
Social and psychological adaptation in a new country can be more or less successful depending on a number of factors. Research into behavioral patterns of migrants residing in Russia has revealed differences in their acculturation strategies and other expressions of migrant ethnic identity. These is a noticeable dependence on types of migrant settlement which can be compact or widespread. Local host population also demonstrates an unequal attitude toward compactly and diffusely settled migrants. This paper describes an attempt to find and analyze correlations between the length of residing in a new ethno-cultural environment, involvement in regional ethnic communities, contact with the host population, and ethnic identity. Differences in adaptation strategies develop three main ethnic identity models. Each model reflects general indicators of migrant adjustability to a new environment and new life.
\end{abstract}

Keywords: migrants; ethnic identity; local community; host population

\section{Introduction}

Intercultural adaptation and acculturation attracted researchers' attention in the early 20th century. Initially, acculturation was determined as a process of long-time communication between bearers of different cultures resulting in social and cultural pattern transformation inside one or more social groups. Later, Graves detailed psychological acculturation at the individual level as changes faced by an individual or a group, ethnic or cultural, interconnecting with other cultures (Graves 1967). Economic globalization trends have resulted in migration flows increasing all over the world and they require cross-cultural cooperation in everyday life (Rudnev 2014). Analyzing migration flows, researchers mostly concentrate on features that help migrants integrate themselves into a new environment. It is also important to examine the host society and major ethnic group in order to understand ethnic relations and interconnection strategies.

Despite the fact that policies of multiculturalism are different in every country, most of them try to administer cultural diversity in a neither racist nor ethnocentric manner and to recreate definitions of self, identity, and a nation. Provided that cultural diversity and the way it is managed are of great importance, analysis of the success of these policies is vital (Ginges and Cairns 2000). At the same time, globalization with its new political and economic reality requires international relations to be more comprehensive and to provide more comfortable living in a multicultural environment.

Today, more than 12 million migrants, or $6.4 \%$ of the total population, reside in Russia. In almost every region, there are communities of Russian-speaking migrants that have come from the former Soviet republics (Florinskaya and Mkrtchyan 2016). The problem of achieving civic solidarity is an age-old problem not only of political philosophy but also of practical, concrete governance in the late modern world. Russia, in this respect, is no exception (Warhola and Lehning 2007). It is very important to understand which adaptation and acculturation models are the most successful and advantageous for further country development. The solution to this problem is tied to understanding 
the psychological characteristics of migrants which change considerably during acculturation. In this context, research of ethnic identity attributes in migrants with different experience of living in the host society and participation in community organizations can help us reveal the role of national communities in acculturation (Konstantinov and Kovaleva 2013).

Living in a multi-ethnic or mono-ethnic community significantly affects ethnic background expression. Interethnic communication, on the one hand, creates more opportunities for an individual to acquire knowledge about the differences in ethnic groups and promotes communication skills. On the other hand, adaptation processes grow under significant social and economic changes and with recognition of people's ethnic identity (Andreouli 2013; Zhang and Noels 2013).

Ethnic identity is researched by many scientists. Erikson, Fromm, Berry, Leman, Sollors, Hartmann, Cornell, and others dedicated their work to different aspects of ethnical identity and ethnicity (Sollors 1996; Hartmann and Cornell 1998; Berry et al. 2002; Berry 2005). Barth considers ethnic groups as culture-bearing units (Barth 1998). According to him, culture is a way to describe human behavior that would follow discrete groups of people, i.e., ethnic units, to correspond to each culture. His conception of ethnic boundaries recognizes those boundaries necessary for ethnic identity preservation.

In the Russian Federation, regional ethnic communities play a significant role in regulation and optimization of interethnic relations on a local level. Regional ethnic communities help their members adapt to the new social, economic, and cultural environment and mitigate existing controversy in national relationships (Konstantinov 2007). As soon as the communities become an empirical base for psychological research, they give a scientific basis for practical work on the elimination of interethnic tension.

In psychology, identity research has become more intense since the 1970s. Personal identity is a definite psychic core, which remains relatively unchanged and self-identical no matter how active the other personal structures are. Identity is a socialized part of the ego (Fromm 2000). Each society is a variety of identities-from a child's or parent's identity to professional, political, and other types of identities. Some of them, i.e., sexual and racial, are imposed from the moment of birth and usually cannot be changed, while others are acquired throughout one's lifetime through social activity and interpersonal relationships (Turner 2003). Identity is the product of self-identification and identification by others.

\section{Materials and Methods}

This research involved 399 residents of the city of Penza and Penza region, Russia, in an age range of 19 to 58. The population was comprised of migrants from Uzbekistan, Tajikistan, Kyrgyzstan, and Azerbaijan residing in the Penza region from 1 to 26 years. This focus group corresponds to general social and demographic parameters. The questionnaire results let us split the participants into four groups.

Group 1-Compactly settled migrants with short residence experience. This group includes migrants living in Russia for less than five years who are part of a regional ethnic community.

Group 2-Diffusely settled migrants with significant residence experience. The group includes those living in Russia for more than five years who avoid regional ethnic communities.

Group 3-Diffusely settled migrants with short residence experience, or migrants residing in Russia for less than five years who avoid regional ethnic communities.

Group 4-Compactly settled migrants with significant residence experience living in Russia for more than five years and who take part in activities of regional ethnic communities.

Acculturation processes and time they require may vary from several months to four or five years depending on individual social and psychological characteristics and in particular on their traditional culture as well as culture new for them. It is understood that the time needed for acculturation to a new ethno-cultural environment is five years, however the majority of people in selected groups have different lengths of residence in Russia, e.g., the first and third groups have an average residence time 
in Russia equal to two years, while in the second and fourth groups average length of residence is about nine years.

The empirical research methodology is based on a systematic approach in psychology according to Ananyev, Barabanschikov, Brushlinskij, Hanzen, Zhuravlev, Lomov, and Kuzmin (Barabanschikov 2007). It means a systematic organizational and interactional method considering social and psychological characteristics of an individual such as an ethnic identity type, acculturation strategy, substantial identity characteristics, and personal values. Ways of achieving the purpose of this research include determination of personality ethnic identity types, an acculturation strategy, behavioral aggressiveness, substantial characteristics of personal identity, and personal values on levels of general ideals and individual priorities. This choice can be explained by the logic of this research based on estimated psychological characteristics which are tied to ethnic identity and include different aspects of self-identification as well as a sense of belonging to a certain ethnic group. General behavioral aggressiveness estimation with the Buss-Durkee Hostility Inventory (the Pochebut's modification, Pochebut 2005) can reveal participant disadaptation. Behavior aggressiveness research is important for ethnic conflict prevention as well as for comprehensive research of ethnic minorities' identity.

The 'types of ethnic identity' method, or TEI, by Soldatova and Ryzhova in modification of Paygunova (Stefanenko et al. 1993) is used to determine ethnic identity indicators. This method helps determine ethnic identity types by considering the kind and strength ethnic tolerance.

According to the Berry's method for determining acculturation strategies, the given research involved migrants revealing their acculturation strategy (Berry 1997). Participants were asked to determine the rank of their agreement with the number of statements and the mean was calculated for each strategy to identify the predominant acculturation strategy.

Participant values contribute to the total image of identification and self-identification and uncover the differences. The Schwartz's value inventory helps to discover an individual value structure and is a theoretically proved method encompassing a wider spectrum of values compared, for example, with the Rokeach's method (Schwartz 2006). The value concept is able to unify the apparently diverse interests of all the sciences concerned with human behavior (Rokeach 1973). The Rokeach's method was taken by Schwartz as an initial point, but he conceptually improved, modified, and enlarged it.

The comprehensive assessment is intended to recognize possible nuances and differences in respondents' ethnic identity.

\section{Results}

The tables below show the results of the Kruskal-Wallis test (Table 1) and the Mann-Whitney test (Tables 2 and 3) being conducted to figure out the difference between ethnic identity types $(\mathrm{H}=288.813$ with $p=0.001$ ), acculturation strategies (separation $\mathrm{H}=294.488$ with $p=0.001$; marginalization $\mathrm{H}=161.158$ with $p=0.001$; integration $\mathrm{H}=302.754$ with $p=0.001$; assimilation $\mathrm{H}=236.590$ with $p=0.001)$, and substantial characteristics of respondents' self-description.

Table 1. The group mean for ethnic identity attributes and acculturation strategies.

\begin{tabular}{ccccc}
\hline Indicators & $\begin{array}{c}\text { Compactly Settled } \\
\text { Migrants with } \\
\text { Short Residence } \\
\text { Experience }\end{array}$ & $\begin{array}{c}\text { Diffusely Settled } \\
\text { Migrants with } \\
\text { Significant Residence } \\
\text { Experience }\end{array}$ & $\begin{array}{c}\text { Diffusely Settled } \\
\text { Migrants with } \\
\text { Short Residence } \\
\text { Experience }\end{array}$ & $\begin{array}{c}\text { Compactly Settled } \\
\text { Migrants with } \\
\text { Significant Residence } \\
\text { Experience }\end{array}$ \\
\hline Ethnic identity & 6.11 & 14.77 & 6.57 & 15.24 \\
Separation & 3.93 & 2.018 & 3.94 & 1.21 \\
Marginalization & 1.2 & 1.74 & 2.78 & 0.99 \\
Integration & 2.31 & 2.81 & 1.77 & 4.018 \\
Assimilation & 1.321 & 2.697 & 2.07 & 2.538 \\
\hline
\end{tabular}

Among the compactly settled migrants with significant residence experience group as well as among the diffusely settled migrants with significant residence experience group, we can see a 
predominance of ethnic identity according to the type of ethnic indifference which is not highly affected by participation in regional ethnic communities.

In both compactly and diffusely settled migrants with short residence experience, there is a predominance of positive ethnic identity as well as hyper-identity in the group of diffusely settled migrants with short residence experience as a consequence of impossibility of adjustment to changing surroundings and other cultural rejection sometimes accompanied with hostility. With a lack of community support, respondents demonstrate nostalgia and exaggeration of ethnic factor significance in everyday communication.

The separation strategy is expressed mostly by the representatives of the compactly settled migrants with the short residence experience group. In most cases, it shows that participation in regional ethnic community life stimulates native identity retention and hampers quicker and closer contact with the host community's identity. Such participation also minimizes stress factors during interaction with another culture.

The marginalization strategy is mostly expressed in respondents with little experience of staying in a receiving ethnic environment and not being involved in regional ethnic community activities. This result can be explained by the fact that stress makes participants reject the regional identity and by the impossibility of accepting another identity.

The integration strategy is mostly shown by the compactly settled migrants with significant residence experience, however it can also be observed in the group of diffusely settled migrants with significant residence experience. The integration strategy is the most adaptive and appropriate because it is the only strategy that supports multicultural ideology and promotes successful adaptation in a new society.

The assimilation strategy is most expressed in both compactly and diffusely settled migrants with significant residence experience. It means that people assimilate into another ethnic environment and this process goes almost irrespectively of their involvement in a regional ethnic community.

So, the longer the residence experience, the higher the ethnic indifference, and the assimilation strategy is more expressed as the dominant acculturation strategy. Involvement in a national community with short experience of staying in another ethnic environment is characterized by the predominance of a positive ethnic identity and a separation strategy. With short-term experience of those staying in a new ethnic environment with a lack of contacts, hyper-identity and separation or marginalization prevail as dominant acculturation strategies.

In order to reveal substantial identity characteristics the Kuhn-McPartland 20 Statements Test (or the "Who am I?" test) can be used pretty successfully. The data analyzed with the Kruskal-Wallis test and Mann-Whitney test can formulate conclusions about differences in substantial identity characteristics.

There are significant differences in the following characteristics:

- the ratio of social roles and individual characteristics $(\mathrm{H}=33.240$ with $p=0.001)$

- $\quad$ self-esteem $(\mathrm{H}=111.086, p=0.001)$

- $\quad$ sexual identity $(\mathrm{H}=47.295, p=0.001)$

- differentiation $(\mathrm{H}=11.383, p=0.001)$

- the "social ego" $(\mathrm{H}=237.707, p=0.001)$

- the "material ego" $(\mathrm{H}=101.109, p=0.001)$

- the "active ego" $(\mathrm{H}=225.725, p=0.001)$

- the "perspective ego" $(\mathrm{H}=20.801, p=0.001)$

- the "reflexive ego" $(\mathrm{H}=50.921, p=0.001)$.

There are no significant differences in the "communicative ego" $(\mathrm{H}=1.669, p=0.644)$ and the "physical ego" ( $\mathrm{H}=5.012, p=0.171)$. 
Table 2. Groups with significant differences compared to each other according to the Mann-Whitney test.

\begin{tabular}{cccc}
\hline Identity Attributes & $\begin{array}{c}\text { Compactly Settled } \\
\text { Migrants, Group 1, and } \\
\text { Diffusely Settled Migrants, } \\
\text { Group 3 }\end{array}$ & $\begin{array}{c}\text { Compactly Settled } \\
\text { Migrants, Group 1, and } \\
\text { Diffusely Settled Migrants, } \\
\text { Group 2 }\end{array}$ & $\begin{array}{c}\text { Compactly Settled } \\
\text { Migrants, Group 1 and 4 }\end{array}$ \\
\hline $\begin{array}{c}\text { Correlation of social } \\
\text { roles and individual } \\
\text { characteristics }\end{array}$ & $\mathrm{U}_{\mathrm{emp}}=4263.000, p=0.001$ & $\mathrm{U}_{\mathrm{emp}}=4648.500, p=0.108$ & $\mathrm{U}_{\mathrm{emp}}=4350.000, p=0.001$ \\
\hline Self-esteem & $\mathrm{U}_{\mathrm{emp}}=2235.000, p=0.001$ & $\mathrm{U}_{\mathrm{emp}}=1509.000, p=0.001$ & $\mathrm{U}_{\mathrm{emp}}=2674.000, p=0.001$ \\
\hline Sexual identity & $\mathrm{U}_{\mathrm{emp}}=5141.500, p=0.992$ & $\mathrm{U}_{\mathrm{emp}}=2997.000, p=0.001$ & $\mathrm{U}_{\mathrm{emp}}=5192.500, p=0.874$ \\
\hline Differentiation & $\mathrm{U}_{\mathrm{emp}}=4991.000, p=0.668$ & $\mathrm{U}_{\mathrm{emp}}=4066.000, p=0.007$ & $\mathrm{U}_{\mathrm{emp}}=5097.000, p=0.673$ \\
\hline Social ego & $\mathrm{U}_{\mathrm{emp}}=379.500, p=0.001$ & $\mathrm{U}_{\mathrm{emp}}=3388.000, p=0.001$ & $\mathrm{U}_{\mathrm{emp}}=495.000, p=0.001$ \\
\hline Material ego & $\mathrm{U}_{\mathrm{emp}}=2121.000, p=0.001$ & $\mathrm{U}_{\mathrm{emp}}=3794.000, p=0.001$ & $\mathrm{U}_{\mathrm{emp}}=1911.000, p=0.001$ \\
\hline Active ego & $\mathrm{U}_{\mathrm{emp}}=5053.000, p=0.001$ & $\mathrm{U}_{\mathrm{emp}}=4934.500, p=0.774$ & $\mathrm{U}_{\mathrm{emp}}=1255.500, p=0.001$ \\
\hline Perspective ego & $\mathrm{U}_{\mathrm{emp}}=83.000, p=0.001$ & $\mathrm{U}_{\mathrm{emp}}=4714.500, p=0.362$ & $\mathrm{U}_{\mathrm{emp}}=3913.000, p=0.001$ \\
\hline Reflexive ego & $\mathrm{U}_{\mathrm{emp}}=4022.500, p=0.005$ & $\mathrm{U}_{\mathrm{emp}}=3657.500, p=0.001$ & $\mathrm{U}_{\mathrm{emp}}=3539.000, p=0.001$ \\
\hline
\end{tabular}

Table 3. Groups with significant differences compared to each other according to the Mann-Whitney test; other pairs.

\begin{tabular}{cccc}
\hline Identity Attributes & $\begin{array}{c}\text { Diffusely Settled Migrants, } \\
\text { Groups 3 and 2 }\end{array}$ & $\begin{array}{c}\text { Diffusely Settled Migrants, } \\
\text { Group 3, and Compactly } \\
\text { Settled Migrants, Group 4 }\end{array}$ & $\begin{array}{c}\text { Compactly Settled } \\
\text { Migrants, Group 4, and } \\
\text { Diffusely Settled Migrants, } \\
\text { Group 2 }\end{array}$ \\
\hline $\begin{array}{c}\text { Correlation of social } \\
\text { roles and individual } \\
\text { characteristics }\end{array}$ & $\mathrm{U}_{\mathrm{emp}}=4263.000, p=0.002$ & $\mathrm{U}_{\mathrm{emp}}=4900.000, p=1.000$ & $\mathrm{U}_{\mathrm{emp}}=4350.000, p=0.002$ \\
\hline Self-esteem & $\mathrm{U}_{\mathrm{emp}}=3557.500, p=0.001$ & $\mathrm{U}_{\mathrm{emp}}=4273.500, p=0.73$ & $\mathrm{U}_{\mathrm{emp}}=2905.500, p=0.001$ \\
\hline Sexual identity & $\mathrm{U}_{\mathrm{emp}}=2799.500, p=0.001$ & $\mathrm{U}_{\mathrm{emp}}=4843.000, p=0.869$ & $\mathrm{U}_{\mathrm{emp}}=2816.500, p=0.001$ \\
\hline Differentiation & $\mathrm{U}_{\mathrm{emp}}=3923.000, p=0.024$ & $\mathrm{U}_{\mathrm{emp}}=4611.000, p=0.402$ & $\mathrm{U}_{\mathrm{emp}}=3746.500, p=0.003$ \\
\hline Social ego & $\mathrm{U}_{\mathrm{emp}}=1209.000, p=0.001$ & $\mathrm{U}_{\mathrm{emp}}=4580.000, p=0.301$ & $\mathrm{U}_{\mathrm{emp}}=1410.000, p=0.001$ \\
\hline Material ego & $\mathrm{U}_{\mathrm{emp}}=2773.000, p=0.001$ & $\mathrm{U}_{\mathrm{emp}}=4780.000, p=0.745$ & $\mathrm{U}_{\mathrm{emp}}=2620.000, p=0.001$ \\
\hline Active ego & $\mathrm{U}_{\mathrm{emp}}=442.000, p=0.001$ & $\mathrm{U}_{\mathrm{emp}}=4457.000, p=0.220$ & $\mathrm{U}_{\mathrm{emp}}=656.500, p=0.001$ \\
\hline Perspective ego & $\mathrm{U}_{\mathrm{emp}}=3786.000, p=0.007$ & $\mathrm{U}_{\mathrm{emp}}=4844.000, p=0.873$ & $\mathrm{U}_{\mathrm{emp}}=3853.500, p=0,007$ \\
\hline Reflexive ego & $\mathrm{U}_{\mathrm{emp}}=2857.000, p=0.001$ & $\mathrm{U}_{\mathrm{emp}}=4398.500, p=0.192$ & $\mathrm{U}_{\mathrm{emp}}=2421.500, p=0.001$ \\
\hline
\end{tabular}

Identity attributes such as the perspective ego, reflexive ego, active ego, and material ego predominate in both compactly and diffusely settled migrants with significant residence experience. Self-description in the mentioned groups includes occupation, career, interests, family, professional success, etc., as well as factors of personal and existential identity, i.e., personal qualities. The social ego attribute is expressed mostly by compactly settled migrants with short residence experience and less by diffusely settled migrants with short residence experience. So, compactly settled migrants with short residence experience demonstrate ethnic and family relationship importance and self-esteem as part of a social group. Such results confirm the fact that a regional ethnic organization, on the one hand, provides a secure feeling, a feeling of belonging to a group, and importance of group membership; on the other hand, it restricts identification in other fields which makes adaptation take longer. The same results are concerned with the differentiation level with less expression in diffusely settled migrants. Migrants who recently moved to Russia and did not participate in the national community were under stress caused by an alien environment, and that impact cannot be reduced by ethnic community support. Disappointment in ethnic community support and assistance can cause separation from a community organization. Compactly settled migrants with short residence experience are leaders in 
self-esteem attribute value which means that they display pretty inflated self-esteem. Correlation in self-description of social roles and individual characteristics shows that both compactly and diffusely settled migrants with significant residence experience demonstrate a well-balanced combination of the above-mentioned traits, while migrants with little residence experience show a predominance of social roles in their self-description. There is no noticeable difference in sexual identity characteristics except the group of compactly settled migrants with short residence experience.

Levels of aggressiveness in the groups were assessed and compared using the Mann-Whitney and Kruskal-Wallis tests (Table 4).

Table 4. The average group level of aggressiveness.

\begin{tabular}{ccccc}
\hline Groups & $\begin{array}{c}\text { Compactly Settled } \\
\text { Migrants, Group 1 }\end{array}$ & $\begin{array}{c}\text { Diffusely Settled } \\
\text { Migrants, Group 3 }\end{array}$ & $\begin{array}{c}\text { Diffusely Settled } \\
\text { Migrants, Group 2 }\end{array}$ & $\begin{array}{c}\text { Compactly Settled } \\
\text { Migrants, Group 4 }\end{array}$ \\
\hline $\begin{array}{c}\text { Level of } \\
\text { aggressiveness }\end{array}$ & 17.8 & 15.9 & 22.2 & 10.3 \\
\hline
\end{tabular}

The group of those who recently moved to Russia and participate in national community life demonstrated the highest rate of aggressiveness. According to the Buss-Durkee Hostility Inventory in the Pochebut's modification, a high level of aggressiveness means low adaptation abilities caused by objective and subjective reasons. For the first months and years in another ethnic environment, the acculturation process is not complete and sometimes quite painful, resulting in psycho-emotional changes including increased aggressiveness.

It is also necessary to determine possible correlations between ethnic identity and the acculturation strategy, aggressiveness level, and values hierarchy. Correlation types are listed below.

1. Between ethnic identity and aggressiveness $\left(r_{s}=-0.4376\right.$ with $\left.p \leq 0.01\right)$ : the more hyper-identity and non-tolerance, the higher aggressiveness. This can be explained with the fact that hyper-identity hampers the adaptation process and consequently provokes aggressive behavior as a result of maladjustment.

2. Between ethnic identity and separation $\left(\mathrm{r}_{\mathrm{s}}=-0.729\right.$ with $\left.p \leq 0.01\right)$ : the higher ethnic indifference is, the lower separation is. Ethnic indifference means indifference to ethnic issues and less possibility of conflicts in communication with other ethnic groups.

3. Between ethnic identity and integration $\left(\mathrm{r}_{\mathrm{s}}=0.728\right.$ with $\left.p \leq 0.01\right)$ : the more expressed ethnic identity factors are, the better integration is. This means that integration is linked to positive ethnic identity and general ethnic indifference.

4. Between ethnic identity and assimilation $\left(r_{s}=0.617\right.$ with $\left.p \leq 0.01\right)$ : the more expressed ethnic identity factors are, the better assimilation is. Merging with the new environment is possible only with an absence of interest in saving one's original ethnic identity.

5. Between ethnic identity and marginalization $\left(\mathrm{r}_{\mathrm{s}}=-0.215\right.$ with $\left.p \leq 0.01\right)$ : the more expressed ethnic identity factors are, the lower marginalization is. This means less importance of ethnic and national problems in everyday life, so an individual confronts the new culture less and has more opportunities to find a place in a new social system.

6. Between aggressiveness and separation $\left(r_{\mathrm{s}}=0.359\right.$ with $\left.p \leq 0.01\right)$ : the higher separation is, the higher aggressiveness is, because separation as the dominating acculturation strategy is expressed in striving to avoid interaction with other cultures. However, since contacts with the new community cannot be completely excluded, it stimulates aggressiveness and decreases adaptation possibilities.

7. Between aggressiveness and integration $\left(\mathrm{r}_{\mathrm{s}}=-0.464\right.$ with $\left.p \leq 0.01\right)$ : the higher integration is, the less aggressive behavior is expressed. When the integration strategy, as the most successful strategy of adaptation, predominates, personal aggressiveness can only be an individual feature but not a maladjustment indicator. 
8. Between aggressiveness and assimilation $\left(r_{\mathrm{s}}=-0.243\right.$ with $\left.p \leq 0.01\right)$ : the higher assimilation is, the less aggressiveness is expressed. Striving to communicate with other ethnic group representatives makes interpersonal relationships more balanced and almost excludes situations where aggression can be demonstrated. This strategy is quite common among migrants with long-term resident experience in another environment.

9. Between aggressiveness and marginalization $\left(\mathrm{r}_{\mathrm{S}}=0.276\right.$ with $\left.p \leq 0.01\right)$ : the higher marginalization is, the higher personal aggressiveness is. This can be explained by the fact that marginalization can be accompanied by discrimination from other ethnic groups. This situation results in personal attitude changes to the new reality and increases aggressiveness as a way of privacy protection.

It is worth considering the separate correlations listed below between ethnic identity types and different values in a personal values hierarchy.

1. Between ethnic identity and the value of conformity $\left(r_{s}=-0.763\right.$ with $\left.p \leq 0.01\right)$ : the higher ethnic identity in migrants is, the less conformity there is. Absence of an ethnic factor as a behavior determining factor makes an individual express more individual internalities and more comfortably interact with other people. In this situation, conformity no longer plays an important role in personal behavior, however it still presents in a value hierarchy.

2. Between ethnic identity and value of traditions $\left(\mathrm{r}_{\mathrm{s}}=-0.725\right.$ with $\left.p \leq 0.01\right)$ : the more ethnic identity is expressed, the less value of traditions in a personal value structure are demonstrated. This negative correlation is quite common, because indifference to ethnic issues leads to universalization of behavior standards according to the receiving community's standards.

3. Between ethnic identity and value of independence $\left(r_{\mathrm{s}}=0.667\right.$ with $\left.p \leq 0.01\right)$ : the less ethnic identity expresses itself, the higher independence in a personal value structure. A person with strong independence value relies less on their ethnic group help. Less importance of ethnic belonging and its attributes makes an individual more independent in decision-making.

4. Between ethnic identity and value of achievements $\left(r_{\mathrm{s}}=0.735\right.$ with $\left.p \leq 0.01\right)$ : the more ethnic identity is expressed, the more achievements are valued. Personal success and self-actualization become more significant than belonging to a certain group in order to survive.

5. Between ethnic identity and value of safety $\left(\mathrm{r}_{\mathrm{s}}=-0.747\right.$ with $\left.p \leq 0.01\right)$ : the higher ethnic identity, the less safety is valued. Safety becomes less important at late stages of acculturation when the critical moment of entry into a new social and cultural environment has been overcome.

\section{Discussion}

The results demonstrate that all the mentioned factors differ for each group. At the same time, those differences are connected to each other and can be combined into ethnic identity models. An identity model aggregates a complex of socio-psychological characteristics and reveals relations between the length of migratory experience and involvement in community activities. Four considered groups of migrants are relevant to three identity models (Table 5).

Table 5. Components of personal identity models in migrants.

\begin{tabular}{|c|c|c|c|}
\hline Components & $\begin{array}{l}\text { The Unsteady Ethnic } \\
\text { Identity Model }\end{array}$ & $\begin{array}{l}\text { The Narrow Ethnic } \\
\text { Identity Model }\end{array}$ & The Ethnic-Indifferent Model \\
\hline Ethnic identity type & $\begin{array}{l}\text { Hyper-identity or positive } \\
\text { ethnic identity }\end{array}$ & Positive ethnic identity & Ethnic indifference \\
\hline Acculturation strategy & $\begin{array}{c}\text { Separation (rarely } \\
\text { marginalization) }\end{array}$ & Separation & Assimilation (rarely separation) \\
\hline Aggressiveness & Average (rarely high) & High & Average or low \\
\hline Identity characteristics & $\begin{array}{l}\text { Self-description contains } \\
\text { indicators of the social ego } \\
\text { and low differentiation }\end{array}$ & $\begin{array}{l}\text { Self-description is } \\
\text { formed indicators of the } \\
\text { social ego }\end{array}$ & $\begin{array}{l}\text { Self-description contains } \\
\text { indicators of the material ego, } \\
\text { the perspective ego, the reflexive } \\
\text { ego, and the active ego }\end{array}$ \\
\hline
\end{tabular}


1. The narrow ethnic identity model. This model is inherent in those recently moved to a new country and also interested in national community life. Their positive ethnic identity is accompanied by the separation acculturation strategy. While keeping their culture, they try to avoid other cultural contacts even though they sometimes might not recognize their behavior. This controversy of inner positive ethnic identity and keeping distance can hamper acculturation and communication and stimulate higher aggressiveness as an expression of maladaptation. Self-description reveals that persons with this behavioral model feel themselves as part of the group of people sharing the same background and appreciate the importance and value of family relationships. On the one hand, participation in their community life makes them feel more secure getting group support, but on the other hand, it restricts their self-identification in other fields and makes adaptation longer yet smooth.

2. The unsteady ethnic identity model. This model is inherent in those who recently moved to another country and find themselves with an absence of contacts within a national community. Individuals with a positive ethnic identity or hyper-identity may choose the strategy of marginalization as a result of impossibility of keeping their original culture. Interest in contacts with other ethnic groups is low, and their aggressiveness level is high. This model is not necessarily realized under the same conditions. Sometimes, a person with inner motivation chooses the separation strategy more successfully. People's self-descriptions usually contain negative characteristics of the social ego such as "jobless", "loser", etc.

3. The ethnic-indifference model. This model, regardless of participation in national community life, exists in individuals with significant experience of residing in another country. Such individuals are ethnically indifferent and prefer the assimilation strategy to completely integrate into a new society. Self-description contains characteristics of the prospective ego, the acting ego, and the material ego. This model is quite common but not the only possible model because it depends on personal qualities.

\section{Conclusions}

There are correlations between ethnic identity, acculturation strategies, and a personal level of aggressiveness as social-psychological characteristics of an individual. Ethnic identity positively correlates with separation and marginalization strategies and aggressiveness while the strategies of integration and assimilation correlate negatively with ethnic identity as well as aggressiveness and marginalization, and separation.

Therefore, socio-psychological characteristics in migrants are noticeably transformed depending on their type of settlement and intensity of contacts with the host population. Specificity of the host society's attitude toward migrants is also affected by their type of settlement-compact or diffuse. In places with diffusely settled migrants, we can see a positive local population attitude toward them. If migrants live compactly with a concentrated ethnic community, we can observe a biased attitude from the local population.

It is obvious that less-densely settled migrants feel more self-responsible, have more meaningful life purpose, and more life satisfaction. Vice versa, compact settlement does not stimulate their faith in life success and ability to control their lives. Their ethnic identity is more expressed, especially if their adaptation experience is short. Their main acculturation strategy is separation.

Generally, low personal tolerance correlates with strong ethnic identity, which can be accompanied by a negative attitude toward other ethnicities. It can be expressed through anxiety, discomfort, low tolerance to different traditions, cultures, lifestyles, and even opinions, especially in front of other ethnic representatives. Low tolerance populations can rarely recognize other ethnic representatives as individuals. Such an attitude obstructs integration, collaboration, and solidarity between ethnoses.

The significance of this study for the local and migrant populations lies in the field of ethnic relations. A lack of information about the compact communities where migrants live quite isolated lives can cause lower tolerance from the side of the host population.

Results of this study can be applied to the development of social projects and programs intended to improve ethnic relations. 
Increasing migration flows requires studying a wide range of host population attitude determinants.

Conflicts of Interest: The author declares no conflict of interest.

\section{References}

Andreouli, Eleni. 2013. Identity and acculturation: The case of naturalised citizens in Britain. Culture $\mathcal{E}$ Psychology 19: 165-83. [CrossRef]

Barabanschikov, Vladimir. 2007. The system approach in psychology. Voprosy Psychologii 2: 145-51.

Barth, Fredrik. 1998. Ethnic Groups and Boundaries: The Social Organization of Culture Difference. Long Grove: Waveland Press. ISBN 9780881339796.

Berry, John W. 2005. Acculturation: Living successfully in two cultures. International Journal of Intercultural Relations 29: 697-712. [CrossRef]

Berry, John W. 1997. Immigration, acculturation, and adaptation. Applied Psychology 46: 5-34. [CrossRef]

Berry, John W., Ype H. Poortinga, Marshall H. Segall, and Pierre R. Dasen. 2002. Cross-Cultural Psychology: Research and Applications. New York: Cambridge University Press. ISBN 9780521762120.

Florinskaya, Yulia, and N. V. Mkrtchyan. 2016. Migration in Russia in 2016. Russian Economic Development 23: 65-69.

Fromm, Erich. 2000. Personality in Modern Culture. Samara: Bahrah-M. (In Russian)

Ginges, Jeremy, and David Cairns. 2000. Social Representations of multiculturalism: A faceted analysis. Journal of Applied Social Psychology 30: 1345-70. [CrossRef]

Graves, Theodore D. 1967. Psychological Acculturation in a Tri-ethnic Community. South-Western Journal of Anthropology 23: 337-50. [CrossRef]

Hartmann, Douglas, and Stephen Cornell. 1998. Ethnicity and Race: Making Identities in a Changing World. London: SAGE Publications. ISBN 0761985018.

Konstantinov, Vsevolod. 2007. Social-Psychological Characteristics of Migrants' Adaptation in Modern Conditions. Penza: Penza State Pedagogical University.

Konstantinov, Vsevolod, and N. A. Kovaleva. 2013. Parting with motherland as a socio-psychological problem of migration. Psikhologicheskii Zhurnal 5: 3-15.

Pochebut, Ludmila. 2005. Social psychology studies in tolerance and identity. Paper presented at the seminar of Issues of Identity in Russian-speaking Diaspora, Helsinki, Finland, 10-11 November.

Rokeach, Milton. 1973. The Nature of Human Values. New York: Free Press. ISBN 0029267501.

Rudnev, Maksim. 2014. Value adaptation among intra-European migrants: Role of country of birth and country of residence. Journal of Cross-Cultural Psychology 45: 1626-42. [CrossRef]

Werne Sollors, ed. 1996. Theories of Ethnicity: A Classical Reader. New York: New York University Press. ISBN 0333642953.

Stefanenko, Tatiana G., Elena I. Shlyagina, and Sergey N. Yeniklopov. 1993. Methods of Ethnopsychological Research. Moscow: Moscow State University. ISBN 5756704183.

Schwartz, Shalom H. 2006. Basic human values: Theory, measurement, and applications. Revue Française de Sociologie 47: 929. [CrossRef]

Turner, John C. 2003. Social Influence. Saint-Petersburg: Piter Publishing House. ISBN 5947230534. (In Russian)

Warhola, James W., and Alex Lehning. 2007. Political order, identity, and security in multinational, multi-religious Russia. Nationalities Papers 35: 933-57. [CrossRef]

Zhang, Rui, and Kimberly A. Noels. 2013. When ethnic identities vary: Cross-situation and within-situation variation, authenticity, and well-being. Journal of Cross-Cultural Psychology 44: 552-73. [CrossRef]

(c) 2017 by the author. Licensee MDPI, Basel, Switzerland. This article is an open access article distributed under the terms and conditions of the Creative Commons Attribution (CC BY) license (http:// creativecommons.org/licenses/by/4.0/). 